\title{
Desempenho de híbridos de tomate de crescimento indeterminado em função de sistemas de condução de plantas
}

\author{
Evandro S Matos'; Fernando H Shirahige²; Paulo César T de Melo² \\ ${ }^{1}$ SYNGENTA SEEDS Ltda, C. Postal 1578, 13256-000 Itatiba-SP; evandro.matos@syngenta.com; ${ }^{2}$ USP-ESALQ, Dep ${ }^{\text {to }}$ Produção \\ Vegetal, C. Postal 9, 13418-900 Piracicaba-SP; fhshirah@usp.br; pctmelo@esalq.usp.br
}

\begin{abstract}
RESUMO
O presente trabalho teve como objetivo avaliar dois sistemas de tutoramento e condução de plantas na produtividade e seus componentes em híbridos de tomateiro dos segmentos Salada Longa Vida e Santa Cruz de crescimento indeterminado, visando ao consumo in natura. Adotou-se o delineamento em blocos ao acaso com os tratamentos em esquema fatorial $5 \times 2$, quatro repetições, sendo avaliados cinco híbridos comerciais, três pertencentes ao grupo Salada Longa Vida ('Alambra', 'Paron' e 'Forty') e dois do grupo Santa Cruz ('Débora Pto' e 'Ellus'), em dois sistemas de condução de plantas (bambu e fitilho). O experimento foi conduzido em condições de campo, em Itatiba (SP), de julho de 2007 a janeiro de 2008. Foram consideradas todas as plantas de cada parcela e avaliaram-se a produtividade total, produtividade comercial, produção por planta, massa média de frutos, número total de frutos, número de frutos comercializáveis, número de frutos das classes ' $3 \mathrm{~A}$ ', ' $2 \mathrm{~A}^{\prime}$ e ' $1 \mathrm{~A}$ ', número de frutos manchado e com lóculo aberto. Não houve interação entre cultivar e sistema de condução de planta para maioria das características avaliadas, exceto número total de frutos, número de frutos comercializáveis e número de frutos da classe ' $2 \mathrm{~A}$ '. O sistema de condução de plantas com uma haste tutorada com fitilho proporcionou incremento na massa média de frutos e número de frutos da classe ' $3 \mathrm{~A}$ ', e decréscimo do número de frutos da classe ' $1 \mathrm{~A}$ ', sem reduzir a produtividade total e comercial quando comparado ao método de condução tradicional no bambu com duas hastes por planta.
\end{abstract}

Palavras-chave: Solanum lycopersicum, tutoramento, manejo cultural, segmentação de mercado.

\begin{abstract}
Performance of tomato hybrids of indeterminate growth depending on training systems

The objective of this work was to determine the effect of training and of two staking systems for plants on yield potential and its components of tomato hybrids of the Salad Extended Shelf Life and Santa Cruz types of indeterminate growth, aiming in natura market. In this experiment we adopted the randomized block design with the treatments in a $5 \times 2$ factorial scheme, and four replications, evaluating three Salad Extended Shelf Life hybrids ('Alambra', 'Paron' and 'Forty') and two Santa Cruz hybrids ('Débora Pto' and 'Ellus') in two plant training systems. The experiments were carried out in Itatiba, São Paulo state, Brazil, from July 2007 to January 2008. All plants of each plot were considered and were evaluated, for both segments, total yield, marketable yield, production per plant, average fruit weight, total number of fruits, number of marketable fruits, number of marketable fruits classified into ' $3 \mathrm{~A}$ ', ' $2 \mathrm{~A}$ ' and ' $1 \mathrm{~A}$ ' classes, number of fruits with blotchy appearance and open locules with exposed seed. There was no interaction between cultivar and plant training system for most characteristics evaluated, except for total number of fruits, number of marketable fruits and number of marketable fruit of ' $2 \mathrm{~A}$ 'class. The training system with one stem per plant and supported by polypropylene ribbon increased average fruit weight and the number of marketable fruits of ' $3 A$ ' class and reduced the number of marketable fruits of ' $1 A$ ' class, without reducing the total and marketable yields compared to the traditional training method (bamboo stakes with two stems per plant).
\end{abstract}

Keywords: Solanum lycopersicum, staking, cultural management, varietal segmentation.

(Recebido para publicação em 18 de fevereiro de 2011; aceito em 24 de maio de 2012) (Received on February 18, 2011; accepted on May 24, 2012)

$\mathrm{O}$ tomate de mesa ou para consumo in natura é produzido em praticamente todas as regiões geográficas do Brasil e em épocas distintas sob diferentes sistemas de cultivo e diferentes níveis de manejo cultural, destacando-se como a segunda hortaliça mais cultivada no mundo sendo superada apenas pela batata. Em 2010, a safra mundial de tomate de mesa e indústria totalizou 145,6 milhões de $t$ em área cultivada de 4,33 milhões de ha e produtividade média de $33,5 \mathrm{t} \mathrm{ha}^{-1}$. O maior produtor mundial foi a China, com 41,8 milhões de t em 0,87 milhões de ha e produtividade de 48,0 $\mathrm{t}$ ha $^{-1}$. O Brasil produziu 3,69 milhões de t, em quase 61 mil ha, colocando-se em $9^{\circ}$ e $13^{\circ}$ lugares, respectivamente, na escala mundial. O segmento de tomate de mesa contribuiu com $63,4 \%$ da produção (2,34 milhões de $t)$ e os $36,6 \%$ restantes destinaram-se ao processamento industrial $(1,35$ milhões de $\mathrm{t}$ ) (FAOSTAT, 2012; IBGE, 2012).

A cadeia produtiva brasileira do tomate vem experimentando importantes transformações desde o final da década passada, orientadas para a sua modernização e aumento da produtividade. Com efeito, a produtividade média brasileira de tomate, no agregado (segmentos de mesa e indústria), vem aumentando de forma significativa e consistente desde o início da década de 1980. Nas décadas de 1980, 1990 e 2000, os rendimentos médios foram de $33,9 \mathrm{tha}^{-1}, 42,0 \mathrm{tha}^{-1} \mathrm{e}$ $57,9 \mathrm{t} \mathrm{ha}^{-1}$, respectivamente. A produtividade média em 2010 foi de $60,5 \mathrm{t} \mathrm{ha}^{-1}$, enquanto que em 1980, foi de apenas 
$30,6 \mathrm{t} \mathrm{ha}^{-1}$. Sendo assim, em três décadas, a produtividade da tomaticultura brasileira incrementou $97,7 \%$.

Uma das medidas que vem sendo adotada pelos tomaticultores tem por objetivo aumentar a produção por hectare de frutos de maior valor comercial por meio de mudanças nos sistemas de condução e tutoramento das plantas em campo. A maioria das cultivares pertencente ao segmento de tomate de mesa possui hábito de crescimento indeterminado, havendo a necessidade de tutorar sua haste ou caule herbáceo na medida em que a planta se desenvolve. Portanto, o tutoramento tem como finalidade dar suporte para o crescimento das plantas, ao mesmo tempo em que possibilita o aumento da ventilação e a iluminação, facilitando também os tratos culturais (Alvarenga, 2004).

No Brasil, o método de tutoramento mais utilizado é o de cerca cruzada ou "V" invertido, o qual consiste em amarrar as plantas em tutores (geralmente são usadas estacas de bambu) dispostos obliquamente ao solo, formando um "V" invertido entre duas filas consecutivas (Fontes \& Silva, 2002). Embora seja o mais utilizado, este método apresenta a desvantagem de proporcionar a formação de uma câmara úmida e quente na parte interna do " $\mathrm{V}$ " invertido, condicionando um ambiente favorável para o desenvolvimento de fungos, além de reduzir a eficiência de aplicação de agroquímicos, os quais não atingem a parte interna do " $\mathrm{V}$ " formado pelas plantas (Wamser et al., 2008).

Uma alternativa a esse método consiste em uma adaptação onde as estacas de bambu são colocadas de forma alternada nos lados opostos da fila dupla. Segundo Alvarenga (2004) esse sistema chamado de 'ziguezague' permite a ventilação, evita a formação de um ambiente úmido e melhora a insolação. Embora esse arranjo espacial reduza os inconvenientes causados pelo método "V" invertido, ainda não é o ideal na prevenção de problemas fitossanitários. Em função disso, foi proposto o uso do tutoramento vertical com estacas de bambu, o qual otimiza a distribuição da radiação solar e a ventilação, reduzindo o período de molhamento foliar, aumentando a eficiência de aplicação de defensivos, tornando menos severa a incidência de doenças (Wamser et al., 2008).

Outra opção à utilização do bambu seria o uso do fitilho de polietileno para o tutoramento vertical das plantas. Por esse sistema, à medida que as plantas crescem, elas vão sendo enroladas no fitilho, o qual é preso na base da planta no solo e na extremidade superior a um fio de arame que suporta a carga de todas as plantas de uma linha de cultivo (Sediyama et al., 2003). Deve ser destacado que, por esse sistema a condução das plantas é feita com uma ou duas hastes por planta. O uso do fitilho de polietileno evita a reinoculação de patógenos na área, uma vez que a cada ciclo da cultura são utilizados fitilhos novos. Outras vantagens apresentadas são a redução da mão-de-obra (Marim et al., 2005) e também o fato de que o custo de fitilho por hectare ser mais barato do que o de bambu.

A rigor, alterações no manejo das plantas pela adoção de métodos de condução, desbaste de frutos e poda apical, dentre outros, podem modificar a relação fonte-dreno, o que proporciona um incremento da produção e aumento do tamanho e massa média de frutos (Shirahige et al., 2010). Tais adequações nas práticas de manejo visam, portanto, o aumento da produtividade bem como do padrão de qualidade dos frutos.

Neste sentido, este trabalho teve como objetivo estudar o desempenho de híbridos de tomateiro dos segmentos Salada Longa Vida e Santa Cruz em dois sistemas de condução de plantas, tutoradas com fitilho e com estacas de bambu, com uma e duas hastes, respectivamente.

\section{MATERIAL E MÉTODOS}

O experimento foi conduzido no período de 30 de julho de 2007 a 04 de janeiro de 2008, em condições de campo na estação experimental da Syngenta Seeds Ltda, município de Itatiba - SP (2301'15"S; 46 $45^{\circ} 00^{\prime}$ "; $755 \mathrm{~m}$ de altitude).

Adotou-se o delineamento em blocos ao acaso com os tratamentos em esquema fatorial $5 \times 2$, e quatro repetições.
Os dez tratamentos correspondem à combinação de cinco híbridos comerciais, sendo três pertencentes ao grupo Salada Longa Vida (SLV) ('Alambra', 'Paron'e 'Forty') e dois do grupo Santa Cruz (SC) ('Débora Pto' e 'Ellus') e dos sistemas de condução (1) com uma planta por cova e duas hastes por planta, tutorada com estaca de bambu ("V" invertido alternado), e (2) com uma planta por cova e uma haste por planta, tutorada com fitilho (vertical em fileira simples); Cada bloco foi constituído por um canteiro com 74,0 $\mathrm{m}$ de comprimento por $0,60 \mathrm{~m}$ de largura. Os canteiros foram dispostos lado a lado e como bordaduras foram instalados canteiros adicionais nas laterais do experimento. Nas extremidades de cada bloco foram deixadas quatro plantas consideradas também como bordadura.

Os tratamentos (híbridos) foram dispostos em parcelas com área de $9,8 \mathrm{~m}^{2}$, sendo que as parcelas onde foi utilizado o tutoramento com estacas de bambu, o espaçamento foi de $0,9 \mathrm{~m}$ entre canteiros, $0,5 \mathrm{~m}$ entre linha dupla e 1,0 $\mathrm{m}$ entre plantas, totalizando 14 plantas por parcela, o que corresponde a uma população de 14.285 plantas por hectare. Nas parcelas onde se utilizou o fitilho, o espaçamento foi de 1,4 m entre canteiros e $0,35 \mathrm{~m}$ entre plantas, totalizando 20 plantas por parcela, correspondendo a uma população de 20.408 plantas por hectare.

O preparo do solo foi feito com aração e duas gradagens. Foi utilizada uma rotoencanteiradora para a confecção dos canteiros. A correção do solo e a adubação de plantio e cobertura foram realizadas de acordo com os resultados da análise de solo, seguindo-se a recomendação de adubação e calagem para o estado de São Paulo (Trani \& Raij, 1996). Os canteiros foram cobertos com filme agrícola de polietileno (mulching) de cor prata. As mudas foram produzidas em estufa agrícola, em bandejas de poliestireno expandido com 128 células e foi utilizado o substrato de fibra de coco. O transplantio das mudas para a área experimental ocorreu em 12 de setembro de 2007, 42 dias após a semeadura, quando as mudas apresentavam quatro folhas definitivas. As adubações de cobertura foram realizadas duas vezes 
por semana a partir de 25 dias após a instalação dos experimentos no local definitivo, utilizando-se fertirrigação localizada por meio de gotejamento. As quantidades de fertilizantes foram distribuídas na área experimental com base no estádio de desenvolvimento da cultura (Alvarenga, 2004), sendo divididas em três fases. Na primeira, da terceira à quinta semana após o transplantio das mudas (SAT), foram aplicados $1,67 \mathrm{~kg}$ de nitrato de cálcio, $1,25 \mathrm{~kg}$ de fosfato monopotássico e $0,535 \mathrm{~kg}$ de nitrato de potássio; na segunda fase, da sexta à $11^{\mathrm{a}}$ SAT, foram aplicados $2,1 \mathrm{~kg}$ de nitrato de cálcio, $1,73 \mathrm{~kg}$ de fosfato monopotássico e $0,945 \mathrm{~kg}$ de nitrato de potássio; e na terceira fase, da $12^{\mathrm{a}}$ a $17^{\mathrm{a}} \mathrm{SAT}$, foram aplicados $1,1 \mathrm{~kg}$ de nitrato de cálcio e $1,74 \mathrm{~kg}$ de nitrato de potássio.

Foram realizadas desbrotas semanais e em todos os tratamentos foram realizadas a poda apical ou capação, sendo efetuada a uma altura de $1,8 \mathrm{~m}$ a $2,2 \mathrm{~m}$, após a emissão do $8^{\circ}$ racemo, para viabilizar a produção de frutos graúdos.

Os frutos foram colhidos no ponto considerado ideal de maturação, reconhecido pela visualização dos frutos quando começavam a se tornar avermelhados. A colheita foi realizada em todas as plantas das parcelas de cada tratamento. A primeira colheita ocorreu em 22 de novembro de 2007, seguida de mais seis em 27/11, 03/12, 10/12, 17/12, 26/12 e 03/01/2008, totalizando sete colheitas durante o ciclo de condução do experimento.

Avaliou-se a produtividade total (PT), produtividade comercial (PC, diferença entre produtividade total e produtividade de frutos não comercializáveis), produção por planta (PP), massa média de frutos (MM), número total de frutos (NTF), número de frutos comercializáveis (NFC), número de frutos das classes ' $3 \mathrm{~A}$ ', ' $2 \mathrm{~A}$ ' e ' $1 \mathrm{~A}$ ', número de frutos manchados pelo sol (MAN) e com lóculo aberto (LAB). Os frutos foram classificados pelo sistema adotado pelo setor produtivo de tomate que separa os frutos em três categorias ('3A', '2A' e '1A') de acordo com o diâmetro transversal (DT). Para o grupo 'SLV' (formato redondo) considerou-se ' $3 \mathrm{~A}$ ' os frutos com DT maior que $85 \mathrm{~mm}$, ' $2 \mathrm{~A}$ ' com DT entre 65 e $85 \mathrm{~mm}$, e frutos ' $1 \mathrm{~A}$ ' com DT entre 65 e $50 \mathrm{~mm}$. Para o tipo 'SC' (formato oblongo) considerou-se ' $3 \mathrm{~A}$ ' os frutos com DT maior que 70 $\mathrm{mm}$, '2A' com DT entre 60 e $70 \mathrm{~mm}$, e frutos ' $1 \mathrm{~A}$ ' com DT entre 60 e $40 \mathrm{~mm}$. Foram considerados como descarte (frutos não comercializáveis) os frutos com doenças fisiológicas ou fitopatológicas, frutos com ataque de inseto-praga e frutos miúdos (DT menor que 50 e $40 \mathrm{~mm}$ para os grupos 'SLV' e 'SC', respectivamente. Esta classificação aproxima-se da proposta pelo Programa Brasileiro para a Modernização da Horticultura (Andreuccetti et al., 2004).

Os dados do número de frutos das classes ' $3 \mathrm{~A}$ ', ' $2 \mathrm{~A}$ ' e ' $1 \mathrm{~A}$ ', número de frutos manchados e com lóculo aberto foram transformados para raiz quadrada de $(\mathrm{x}+1)$. Posteriormente, as variáveis estudadas foram submetidas à análise de variância (teste F). Havendo significância estatística ( $\mathrm{p} \geq 0,05)$, as médias foram comparadas pelo teste de Tukey a 5\% de significância. As análises estatísticas foram realizadas pelo programa SISVAR, v. 4.3 (Ferreira, 2003).

\section{RESULTADOS E DISCUSSÃO}

Pela análise de variância dos fatores estudados não houve efeito significativo da interação entre cultivar e sistema de condução de plantas para maioria das características avaliadas, exceto número total de frutos, número de frutos comercializáveis e número de frutos da classe ' $2 \mathrm{~A}$ '.

Não houve efeito do sistema de condução sobre a produtividade total (PT) e comercial de frutos (PC) (Tabela 1). Isso indica que, neste experimento, a média de todas as cultivares avaliadas de ambos os grupos de mercado no tutoramento com fitilho com uma haste por planta, alcançou a mesma PT e PC em relação ao sistema de condução com estacas de bambu com duas hastes por planta. Tal resultado evidencia tendência de vantagem com a utilização de uma haste por planta, apesar de que nesse sistema de condução o número de hastes por hectare ser $40 \%$ menor. Resultado semelhante foi obtido por Marim et al. (2005), que não encontraram diferença entre os métodos de tutoramento cruzado e vertical para produtividade total e comercial de frutos. Porém, Wamser et al. (2007), avaliando a produtividade do tomateiro em função dos sistemas de condução de plantas, encontraram incremento na produtividade total e

Tabela 1. Produtividade total (PT), produtividade comercial (PC), produção por planta (PP), massa média de frutos (MM), número de frutos das classes '3A' (3A) e '1A' (1A), número de frutos manchados (MAN) e com lóculo aberto (LAB), das cultivares de tomate dos segmentos Salada Longa Vida e Santa Cruz, para o sistema de condução no bambu e fitilho [total yield (PT), marketable yield (PC), production per plant (PP), average fruit weight (MM), number of marketable fruits of classes ' $3 \mathrm{~A}^{\prime}$ ' $\left.3 \mathrm{~A}\right)$ and ' $1 \mathrm{~A}$ ' $(1 \mathrm{~A})$, number of fruits with blotchy appearance (MAN) and open locules with exposed seed (LAB), of Salada Extended Shelf Life and Santa Cruz tomato types, depending on the staking system with bamboo and polypropylene wire]. Itatiba, Syngenta Seeds, 2007/2008.

\begin{tabular}{|c|c|c|c|c|c|c|c|c|}
\hline \multirow{2}{*}{ Sistemas de condução } & PT & PC & \multirow{2}{*}{$\begin{array}{c}\text { PP } \\
\text { (kg/planta) }\end{array}$} & \multirow{2}{*}{$\begin{array}{c}\text { MM } \\
\text { (g/fruto) }\end{array}$} & $3 A^{2}$ & $1 A^{2}$ & $\mathbf{M A N}^{2}$ & $\mathbf{L A B}^{2}$ \\
\hline & \multicolumn{2}{|c|}{ (t/ha) } & & & \multicolumn{4}{|c|}{ (frutos/planta) } \\
\hline Bambu & $95,7 \mathrm{a}^{1}$ & $94,9 \mathrm{a}$ & $6,7 \mathrm{a}$ & $132,3 \mathrm{~b}$ & $6,6 b$ & $13,7 \mathrm{a}$ & $0,2 \mathrm{~b}$ & $0,1 \mathrm{a}$ \\
\hline Fitilho & $96,5 \mathrm{a}$ & $94,5 \mathrm{a}$ & $4,7 \mathrm{~b}$ & $153,5 \mathrm{a}$ & $8,2 \mathrm{a}$ & $4,4 \mathrm{~b}$ & $0,2 \mathrm{a}$ & $0,1 \mathrm{a}$ \\
\hline CV (\%) & 8,7 & 8,8 & 8,9 & 4,6 & 4,4 & 7,9 & 6,2 & 4,8 \\
\hline
\end{tabular}

${ }^{1}$ Médias na coluna seguidas de mesma letra, não diferem entre si, pelo teste de Tukey a $5 \%$ (means followed by the same letter in the column do not differ according to Tukey's test at the $5 \%$ level of probability); ${ }^{2}$ Os dados originais foram transformados em $\sqrt{\mathrm{x}+1}$ (original data, transformed in $\sqrt{\mathrm{x}+1}$ ). 
Tabela 2. Produtividade total (PT), produtividade comercial (PC), produção por planta (PP), massa média de frutos (MM), número de

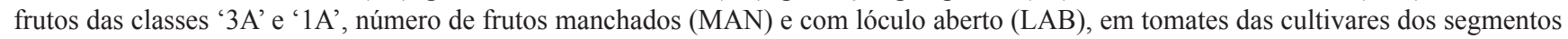
Salada Longa Vida (SLV) e Santa Cruz (SC) [total yield (PT), marketable yield (PC), production per plant (PP), average fruit weight (MM), number of marketable fruits of classes ' $3 \mathrm{~A}^{\prime}$ ' and ' $1 \mathrm{~A}$ ', number of fruits with blotchy appearance (MAN) and open locules with exposed seed (LAB), of tomato fruits depending on cultivars of Salada Extended Shelf Life (SLV) and Santa Cruz (SC) tomato types]. Itatiba, Syngenta Seeds, 2007/2008.

\begin{tabular}{|c|c|c|c|c|c|c|c|c|c|}
\hline \multirow{2}{*}{ Cultivar } & \multirow{2}{*}{ Tipo } & PT & $\mathbf{P C}$ & \multirow{2}{*}{$\underset{\text { (kg/planta) }}{\text { PP }}$} & \multirow{2}{*}{$\underset{\text { (g/fruto) }}{\text { MM }}$} & $3 \mathbf{A}^{2}$ & $1 \mathrm{~A}^{2}$ & MAN $^{2}$ & $\mathbf{L A B}^{2}$ \\
\hline & & & & & & \multicolumn{4}{|c|}{ (frutos/planta) } \\
\hline Alambra & SLV & $103,3 \mathrm{a}^{1}$ & $100,8 \mathrm{a}$ & $6,0 \mathrm{a}$ & $148,9 \mathrm{~b}$ & $2,7 \mathrm{~b}$ & $11,6 \mathrm{a}$ & $0,3 \mathrm{a}$ & $0,1 \mathrm{~b}$ \\
\hline Paron & SLV & $97,0 \mathrm{ab}$ & $95,6 a b$ & $5,8 \mathrm{ab}$ & $164,2 \mathrm{a}$ & $2,6 \mathrm{~b}$ & $10,0, a$ & $0,0 \mathrm{~b}$ & $0,3 \mathrm{a}$ \\
\hline Forty & SLV & $97,6 \mathrm{ab}$ & $95,7 \mathrm{ab}$ & $5,8 \mathrm{ab}$ & $151,1 \mathrm{~b}$ & $3,3 \mathrm{~b}$ & $10,8 \mathrm{a}$ & $0,3 \mathrm{a}$ & $0,2 \mathrm{a}$ \\
\hline Débora Pto & $\mathrm{SC}$ & $89,2 \mathrm{~b}$ & $88,6 \mathrm{c}$ & $5,3 \mathrm{~b}$ & $127,1 \mathrm{c}$ & $13,7 \mathrm{a}$ & $6,2 \mathrm{~b}$ & $0,2 \mathrm{ab}$ & $0,0 \mathrm{~b}$ \\
\hline Ellus & $\mathrm{SC}$ & $93,4 \mathrm{ab}$ & $92,9 \mathrm{bc}$ & $5,5 \mathrm{ab}$ & $123,1 \mathrm{c}$ & $14,7 \mathrm{a}$ & $7,8 \mathrm{~b}$ & $0,2 \mathrm{ab}$ & $0,0 \mathrm{~b}$ \\
\hline CV (\%) & & 8,7 & 8,8 & 8,9 & 4,6 & 4,4 & 7,9 & 6,2 & 4,8 \\
\hline
\end{tabular}

${ }^{1}$ Médias na coluna seguidas de mesma letra não diferem entre si pelo teste de Tukey a $5 \%$ (means followed by the same letter in the column do not differ according to Tukey's test at the 5\% level of probability); ${ }^{2}$ Os dados originais foram transformados em $\sqrt{\mathrm{x}+1}$ (original data, transformed in $\sqrt{\mathrm{x}+1}$ ).

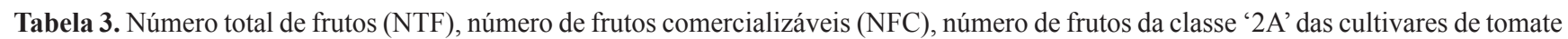
dos segmentos Salada Longa Vida (SLV) e Santa Cruz (SC), em função do sistema de condução de plantas [total number of fruits (NTF), number of marketable fruits (NFC) and number of marketable fruits of class '2A' of Salada Extended Shelf Life (SLV) and Santa Cruz (SC) tomato types, depending on the training system]. Itatiba, Syngenta Seeds, 2007/2008.

\begin{tabular}{|c|c|c|c|c|c|c|c|}
\hline \multirow{2}{*}{ Cultivar } & \multirow{2}{*}{ Tipo } & Bambu & Fitilho & Bambu & Fitilho & Bambu & Fitilho \\
\hline & & \multicolumn{2}{|c|}{ NTF (frutos planta ${ }^{-1}$ ) } & \multicolumn{2}{|c|}{ NFC (frutos planta ${ }^{-1}$ ) } & \multicolumn{2}{|c|}{$2 \mathrm{~A}^{2}\left(\right.$ frutos planta $\left.{ }^{-1}\right)$} \\
\hline Alambra & SLV & $52,1 \mathrm{bcA}^{1}$ & $30,3 \mathrm{abB}$ & $51,8 \mathrm{bcA}$ & $29,9 \mathrm{abB}$ & $31,8 \mathrm{aA}$ & $21,2 \mathrm{aB}$ \\
\hline Paron & SLV & $43,9 \mathrm{dA}$ & $27,3 \mathrm{bB}$ & $43,6 \mathrm{dA}$ & $26,9 \mathrm{bB}$ & $28,8 \mathrm{aA}$ & $19,3 \mathrm{abB}$ \\
\hline Forty & SLV & $47,2 \mathrm{cdA}$ & $30,3 \mathrm{abB}$ & $46,8 \mathrm{cdA}$ & $29,6 \mathrm{abB}$ & $29,1 \mathrm{aA}$ & $19,2 \mathrm{abB}$ \\
\hline Débora Pto & $\mathrm{SC}$ & $54,8 \mathrm{abA}$ & $31,4 \mathrm{abB}$ & $54,6 \mathrm{abA}$ & $31,1 \mathrm{abB}$ & $32,1 \mathrm{aA}$ & $13,7 \mathrm{cB}$ \\
\hline Ellus & $\mathrm{SC}$ & $58,3 \mathrm{aA}$ & $34,0 \mathrm{aB}$ & $58,1 \mathrm{aA}$ & $33,9 \mathrm{aB}$ & $31,5 \mathrm{aA}$ & $15,3 \mathrm{bcB}$ \\
\hline $\mathrm{CV}(\%)$ & & \multicolumn{2}{|c|}{7,3} & \multicolumn{2}{|c|}{7,3} & \multicolumn{2}{|c|}{5,2} \\
\hline
\end{tabular}

${ }^{1}$ Médias seguidas pelas mesmas letras minúsculas na coluna e maiúsculas na linha não diferem entre si pelo teste de Tukey a 5\% (mean values followed by same lower case letter in the columns and upper case in rows, do not differ by Tukey test, at $5 \%$ probability); ${ }^{2}$ Os dados originais foram transformados em $\sqrt{\mathrm{x}+1}$ (original data, transformed in $\sqrt{\mathrm{x}+1}$ ).

comercial em todos os métodos de tutoramento vertical avaliados.

No presente trabalho, verificou-se que o tutoramento com fitilho com uma haste por planta em relação ao sistema de condução com estacas de bambu com duas hastes por planta, proporcionou incremento de $23,6 \%$ e redução de $68,0 \%$ no número de frutos das classes ' 3 A' e '1A', respectivamente (Tabela 1). Resultados similares foram reportados por Carvalho \& Tessarioli Neto (2005) e Marim et al. (2005), que observaram acréscimo na produtividade de frutos de melhor classificação (frutos grandes) e decréscimo na produtividade de frutos pequenos com a condução de uma haste por planta. Os autores atribuem essa diferença à maior insolação e ventilação propiciadas pelo método de tutoramento vertical. Wamser et al. (2007) avaliaram a produção do tomateiro em função dos sistemas de condução de plantas, concluíram que os métodos de condução com uma haste por planta proporcionam maior produção de frutos grandes e qualidade de tomates em relação ao método de condução com duas hastes. Tais resultados têm grande importância para o produtor, pois os frutos de maior tamanho são aqueles que alcançam maiores preços no mercado para consumo in natura.

Dentro de cada segmento 'SLV' e 'SC', os híbridos não diferiram estatisticamente entre si para PT, PC, PP, número de frutos das classes ' $3 \mathrm{~A}$ ' e '1A' (Tabela 2). No entanto, o híbrido Alambra apresentou PT superior ao 'Débora Pto' em 15,7\%, e maior PC que 'Débora Pto' e 'Ellus', em 13,7\% e $8,5 \%$, respectivamente. Para número de frutos da classe ' $3 \mathrm{~A}$ ', os híbridos de tomate do tipo 'SC' Débora Pto e Ellus foram superiores às cultivares do segmento 'SLV' (Tabela 2), o que evidencia a diferença do potencial produtivo de frutos graúdos entre os dois grupos de tomate avaliados. Situação oposta ocorreu para o número de frutos da classe '1A' (Tabela 2).

O sistema de condução tradicional com estacas de bambu influenciou o número total de frutos, número de 
frutos comercializáveis, produção por planta e massa média de frutos. Independentemente das cultivares, as plantas conduzidas por esse sistema apresentaram desempenho superior para NTF, NFC e PP, e inferior para a MM (Tabelas 3 e 1) quando comparada ao sistema de condução vertical no fitilho. Uma provável explicação para tal ocorrência deve estar relacionada ao fato de as plantas tutoradas com bambu terem sido conduzidas com duas hastes, enquanto que as plantas tutoradas com fitilho foram produzidas com uma haste. $\mathrm{O}$ aumento no número total de frutos e na produção por planta, e a menor massa média de frutos das plantas no sistema com duas hastes, ao que parece, ocorreu em função do maior número de haste por planta e pela maior competição entre os frutos pelos fotoassimilados, respectivamente. Quando se aumenta o número de frutos por planta, a demanda de fotoassimilados pelos frutos se eleva, instalando-se uma forte competição por assimilados entre esses. Shirahige et al. (2010), avaliando tomates dos segmentos Santa Cruz e Italiano verificaram que as plantas não submetidas ao raleio de fruto com maior número de frutos por planta obtiveram menor massa média de frutos. Esse resultado é corroborado por Carvalho \& Tessarioli Neto (2005) que estudaram diferentes cultivares de tomate em função do espaçamento e número de hastes por planta. Esses autores chegaram à conclusão que independentemente dos híbridos, as plantas conduzidas com duas hastes apresentaram maior número de frutos por planta e menor massa média comercial de frutos. Resultados semelhantes são também descritos por Seleguini et al. (2002) que reportaram maior número total de frutos e de frutos comercializáveis no sistema de condução com duas hastes em relação àquelas cultivadas com uma haste. Portanto, ao que tudo indica, o incremento do número de frutos por planta é função do maior número de hastes por planta.

Na produção por planta, a cultivar do tipo 'SLV' Alambra mostrou desempenho superior em 14,8\% em relação ao híbrido 'SC' Débora Pto, conforme pode ser visto na Tabela 2.

Para massa média de frutos, o híbrido 'SLV' Paron com MM de 164,2 g fruto $^{-1}$ foi superior às demais cultivares independentemente do grupo varietal. 'Alambra' com MM de 148,9 g fruto $^{-1}$ e 'Forty' com 151,1 g fruto ${ }^{-1}$, não diferiram entre si, mas foram superiores às cultivares ' $\mathrm{SC}$ ' Débora Pto e Ellus (Tabela 2). Há uma tendência de que as cultivares pertencentes ao grupo 'SLV' (valores médios de MM de 154,7 g fruto $^{-1}$ ) apresentam MM 23,65\% superiores em comparação aquelas do grupo ' $\mathrm{SC}$ ' (valores médios de $\mathrm{MM}$ de 125,1 g fruto $^{-1}$ ) (Tabela 2). As diferenças de MM entre os grupos 'SLV' e 'SC' já eram previsíveis uma vez que as cultivares do grupo 'SLV' mostram geralmente características distintas do grupo ' $\mathrm{SC}$ ' em termos de formato, tamanho e massa média de frutos (Epagri, 2003).

Houve maior número de frutos manchados $(35,3 \%)$ no sistema de condução no fitilho com uma haste por planta quando comparado ao tutoramento com estacas de bambu com duas hastes por planta (Tabela 1). O sistema de condução vertical no fitilho com uma haste por planta favorece o surgimento de frutos manchados. Isso ocorre devido à menor proteção dos frutos pelas folhas contra a incidência direta de radiação solar (Alvarenga, 2004). Com relação aos híbridos, 'Paron' foi significativamente inferior ao 'Alambra' e 'Forty' mas não diferiu significativamente de 'Débora Pto' e 'Ellus' (Tabela 2). Uma provável explicação para tal ocorrência pode estar relacionada ao melhor enfolhamento desse híbrido.

Não houve efeito entre os sistemas de condução de plantas para lóculo aberto (Tabela 1). No entanto, ocorreu diferença estatística entre os híbridos evidenciando a diferença genética entre os grupos de mercado avaliados (Tabela 2). O número de frutos com lóculo aberto para os híbridos Paron e Forty foi significativamente superior ao de 'Alambra'(Tabela 2). Esse resultado mostra que 'Paron' e 'Forty', aparentemente, têm uma maior predisposição genética para apresentar este tipo de distúrbio fisiológico do que 'Alambra'. Esse híbrido, por sua vez, não diferiu de 'Débora Pto' e 'Ellus', indicando, de fato, ser mais tolerante à ocorrência dessa desordem. Melo et al. (2005) afirmam que a expressão desse distúrbio está associada, dentre outros fatores, à cultivar.

É importante ressaltar que a ocorrência quase nula de lóculo aberto observada nos dois híbridos Santa Cruz já era previsível, pois de acordo com Alvarenga (2004), o grupo salada apresenta maior suscetibilidade ao lóculo aberto devido ao maior número de lóculos.

No sistema de condução com bambu o híbrido Ellus alcançou maior NTF e NFC que as cultivares do segmento 'SLV'. Porém, no tutoramento com fitilho, 'Ellus' mostrou-se superior apenas ao híbrido Paron (Tabela 3) para ambas as características avaliadas.

Para o número de frutos da classe ' $2 \mathrm{~A}$ ', no sistema de condução com bambu, todas as cultivares avaliadas obtiveram maior número de frutos da classe ' $2 \mathrm{~A}$ ' quando comparado às plantas tutoradas com fitilho (Tabela 3 ). Esse resultado se deve, ao que tudo indica, pelo maior NTF (Tabela 3) alcançado nas plantas com duas hastes por planta (condução no bambu) e à maior competição entre os frutos pelos fotoassimilados, com consequente redução na massa média de frutos (Tabela 1). No sistema de condução no fitilho, o híbrido Débora Pto destacou-se por exibir menor número de frutos da classe '2A' que as cultivares Alambra, Paron e Forty. Já 'Ellus' produziu menor número de frutos da classe '2A' que a cultivar Alambra. No tutoramento com estacas de bambu não houve diferença significativa entre os desempenhos dos híbridos avaliados (Tabela 3).

Com base nestes resultados conclui-se que o sistema de tutoramento vertical no fitilho com uma haste por planta aumenta a produtividade de frutos de melhor classificação (classe ' $3 A^{\prime}$ '), bem como a massa média de frutos, e reduz a produtividade de frutos de classificação inferior (classe ' $1 \mathrm{~A}^{\prime}$ '), sem diminuir a produtividade total e comercial quando comparada ao método de condução tradicional no bambu com duas hastes por planta.

Dentro do segmento 'SC', os híbridos avaliados não diferiram estatisticamente entre si para todas as características avaliadas independente do sistema de condução. Por sua vez, os híbridos 'SLV' não diferiram entre si quanto à 
PT, PC, PP, número de frutos das classes ' $3 \mathrm{~A}$ ' e '1A'. O híbrido Paron sobressaiu-se por apresentar maior massa média de frutos e menor número de frutos manchados que 'Alambra' e 'Forty', mas não diferiu desses híbridos para NTF e NFC no sistema de condução no fitilho com uma haste por planta.

\section{REFERÊNCIAS}

ALVARENGA MAR. 2004. Tomate: produção em campo, em casa-de-vegetação e em hidroponia. Lavras: Edit. UFLA, 400p.

ANDREUCCETTI C; FERREIRA MD; GUTIERREZ ASD; TAVARES M. 2004. Classificação e padronização do tomate cv. Carmen e Débora dentro da CEAGESP-SP. Engenharia Agrícola 24: 790-798.

CARVALHO LA; TESSARIOLI NETO J. 2005. Produtividade de tomate em ambiente protegido, em função do espaçamento e número de ramos por planta. Horticultura Brasileira 23: 986-989.

EPAGRI. 2003. Avaliação de cultivares para o Estado de Santa Catarina 2003/2004. Florianópolis: Epagri. 141p.

FAOSTAT - FAO Statistics Division. 2012, 4 de janeiro. Disponível em: http://faostat.fao.org/ site/567/default.aspx\#ancor.

FERREIRA DF. 2003. SISVAR 4. 3 - Sistema de análises estatísticas. Lavras: UFLA.

FONTES PCR; SILVA DJH. 2002. Produção de tomate de mesa. Viçosa: Aprenda Fácil, 193p.

IBGE - Instituto Brasileiro de Geografia e Estatística. 2012, 6 de janeiro. Levantamento sistemático da produção agrícola. 2011. Disponível em: http://www.ibge.gov.br/home/ estatistica/indicadores/agropecuaria/lspa/ 1spa_201111.pdf.

MARIM BG; SILVA DJH; GUIMARÃES MA; BELFORT G. 2005. Sistemas de tutoramento e condução do tomateiro visando produção de frutos para consumo in natura. Horticultura Brasileira 23: 951-955.

MELO PCT; LOPES CA; GIORDANO LB. 2005. Distúrbios fisiológicos. In: LOPES CA; ÁVILA AC. (ed). Doenças do tomateiro. Brasília: EMBRAPA Hortaliças. p. 101-132.

SEDIYAMA MAN; FONTES PCR; SILVA DJH. 2003. Práticas culturais adequadas ao tomateiro. Informe Agropecuário 24: 19-25.
SELEGUINI A; SENO S; ZIZAS GB. 2002. Influência do espaçamento entre plantas e número de cachos por planta na cultura do tomateiro, em condições de ambiente protegido. In: CONGRESSO BRASILEIRO DE OLERICULTURA, 42. Resumos... Uberlândia: SOB. (CD-ROM).

SHIRAHIGE FH; MELO AMT; PURQUERIO LFV; CARVALHO CRL; MELO PCT. 2010. Produtividade e qualidade de tomates Santa Cruz e Italiano em função do raleio de frutos. Horticultura Brasileira 28: 292-298.

TRANI PE; RAIJ B. 1996. Hortaliças. In: RAIJ B; CANTARELLA H; QUAGGIO JA; FURLANI AMC. Recomendações de adubação e calagem para o estado de São Paulo. Campinas: IAC. p.157-186. (Boletim Técnico 100).

WAMSER AF; BECKER WF; SANTOS JP; MUELLER S. 2008. Influência do sistema de condução do tomateiro sobre a incidência de doenças e insetos-praga. Horticultura Brasileira 26: 180-185.

WAMSER AF; MUELLER S; BECKER WF; SANTOS JP. 2007. Produção do tomateiro em função dos sistemas de condução de plantas. Horticultura Brasileira 25: 238-243. 